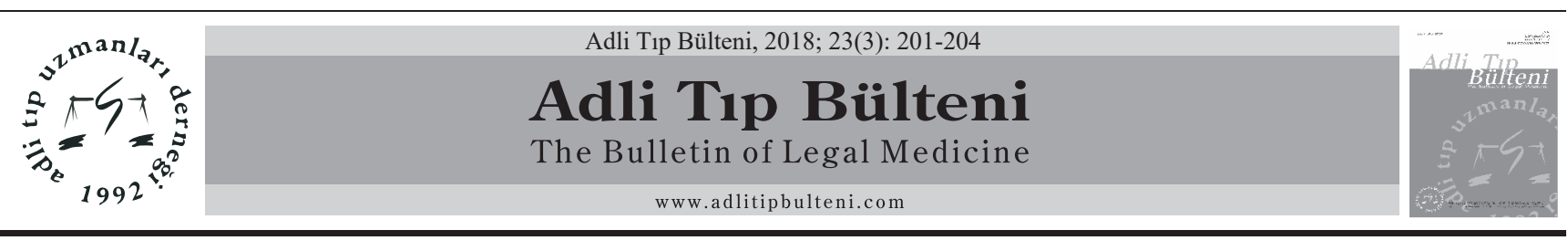

OLGU SUNUMLARI

doi: $10.17986 /$ blm.2018345607

\title{
Dövmenin (Tatuaj) Lazerle Silinmesi Hekim Sorumluluğu: Bir Olgu Sunumu
}

\section{Laser Tattoo (Tattooing) Removal with Responsibility of The Doctor: A Case Report}

\author{
Ebru Yolaçan, Gülşah Dağ Oğlakcıoğlu, Gürol Cantürk
}

Ankara Üniversitesi Tıp Fakültesi Adli Tıp Anabilim Dall, Ankara

\section{Özet}

Dövme (tatuaj) çok eski tarihlerden günümüze süregelen bir uygulamadır. Dövme topluluklar için bir inancı, toplumsal sınıfı veya kimliği temsil eder. Dövme insan vücuduna farklı desen ve renklerde uygulanmaktadır. Bunların bir kısmı geçiciyken bir kısmı da kalıcıdır. Derinin alt tabakasına enjekte edilen mürekkep dövmenin kalıcı olmasını sağlar. Tatuaj son yıllarda gençler arasında yaygınlık kazanmıştır. Yaygınlaşmayla birlikte daha sonra dövmeyi sildirmek isteyenlerin artmasına bağlı olarak bilim adamları dövme silme yöntemleri üzerine değişik tedavi arayışlarına girmiştir. Bu yöntemlerden bazıları; dermabrazyon, kriyocerrahi, elektrocerrahi ve cerrahi eksizyon gibi tahrip edici tekniklerdir. Bunların yan etkisi oldukça fazla olduğundan son yıllarda lazer teknolojisi gelişmiştir. Günümüzde dövme sildirmek için kullanılan en yaygın yöntem Q-anahtarlı lazer yöntemidir. Birkaç seansta farklı dalga boyları ve sıklığıyla farklı renklere müdahale edilerek dövme boyasının parçalanması hedeflenir. Bu olgu sunumunda, hasta 2015 y1lında koluna ve el bileğine dövme yaptırmıştır. 2016 yılında dövme silinmesi için bir merkeze başvurmuştur. Doktor hastaya hastanın bahsi geçen dövmelerin lazerle tamamen silineceğine dair imzalı bir belge vermiştir. Dövmelerde bütünüyle silinme gerçekleşmeyince hasta Tıp Fakültemizin Adli Tıp Anabilim Dalına mahkeme tarafından gönderilmiştir. Olgu hekim sorumluluğu açısından değerlendirildiğinde Türk Borçlar Kanunu 7. Bölüm (Eser Sözleşmesi) Madde 470' de yer alan ölçütler ve Yargitay’ın 15. HD. 3.11.1999, 4007 E./3868 karar metni göz önüne alındığında eser sözleşmesi kapsamında hekimin sonucu garanti ettiği tıbbi müdahalelerden biri olarak değerlendirilmiştir. Hastanın başvuru nedeni-isteği göz önüne alındığında ve istek doğrultusunda gerekli tıbbi işlemlere başlandığında sonuç garanti edilmiş olmaktadır. Bu tür olgularda aydınlatılmış onam özellikle önem arz etmektedir.

Anahtar Kelimeler: Dövme; Lazer; Eser Sözleşmesi; Hekim Sorumluluğu.

\begin{abstract}
Tattoo (tattooing) is a practice that continued from ancient times to modern-day. It represents a belief for communities, a social class or the identity. Tattoo is applied to human body in different patterns and colors. Some of the mare temporary while others are permanent. The ink injected into the dermis layer ensures that tattoo is permanent. Tattooing has gained prevalence among young people in recent years. Associated with prevalent, later, depending on the increase of those who want to be removed tattoo, scientists have searched for different treatments on tattoo removal methods. Some of these methods are destructive techniques such as dermabrasion, cryosurgery, electrosurgery and surgical excision. Since they have a lot of side effects, laser technology has advanced in recent years. The most common method used today for tattoo removal is the Qswitched laser method. A few clinics are aimed at disintegrating the tattoo painting by interfering with different colors via different wave length and frequency. In this case report, the patient had tattoos on the arm and the wrist in 2015. He consulted health center to be eradicated his tattoos in 2016. The physician gave a signed document on completely eradicated his tattoos by the laser to the patient. By virtue of the fact that case's body did not purely removal the tattoos, the patient was dispatched our Medical Faculty, Department of Forensic Science by court. When the case evaluate from the point of responsibility of the doctor, to be considering the criteria contained Chapter 7 (the contract of work) Article 470 of the Turkish Obligations Code and Court of Appeals 15th HD 3.11.1999, 4007 E./3868 decision text, as part of contract for work is evaluated as one of the medical intervention which the physician guarantees the end result. When the patient application's reason/request is considered and necessary medical procedures are started on request, the result is guaranteed. In such a case, informed consent is of particular importance.
\end{abstract}

Keywords: Tattoo; Laser; Contract for Work; Responsibility of the Doctor.

Sorumlu Yazar: Prof. Dr. Gürol Cantürk

Ankara Üniversitesi Tip Fakültesi Adli Tip Anabilim Dall, Ankara

E-mail:gurolcanturk@yahoo.com

*Bu çalışmanın bir bölümü, 12-15 Nisan 2018 tarihleri arasında gerçekleşen 15. Adli Bilimler Kongresinde poster bildirisi olarak sunulmuştur.

Geliș: 21.05.2018 Düzeltme: 31.05.2018 Kabul: 12.06.2018

\section{Giriş}

Dövme kelimesi Tahiti dilindeki "tatau” dan gelmektedir. İlk kez İngiliz gezgini James Cook tarafindan tan1tılmıştır. Batı Dünyasında ticari sektör haline gelmesini sağlayan Britanyalılardır (1). Tatuaj çok eski yıllardan 
günümüze kadar varlığını devam ettiren bir uygulamadır. Dövme eski zamanlarda kimi toplumlar için aristokratllğ temsil ederken, kimileri içinse ahlaksızlığı, köleliği temsil ederdi. Günümüzde ise profesyonel, amatör ve kozmetik amaçlı kullanılmaktadır. Hatta resüsitasyon istemeyen kanser hastaları acil tıbbi bir durumda sağlık görevlisinin uyarılması için vücuduna "DNR (do not resuscitate)" yazdirabilmektedir (2).

Dövme insan vücudunda kalıcı ya da geçici şekiller ve desenler oluşturur. Kalıcı dövme oluşturma mekanizması dövme iğnesindeki mürekkebin derinin dermis tabakasına enjekte edilmesiyle ekzojen olarak makrofaj, mast hücresi ve fibroblast hücrelerine yerleştirilmesidir. Vücuda giren yabancı maddeye ilk tepki, savunma hücremiz olan makrofajlar tarafından verilir. Dövme boyasını fagosite eden makrofajlar boyayı daha küçük parçalara ayırır ve lenf nodlarıyla uzaklaştırılır. Uzaklaştırılamayan parçalar derinin dermis tabakasında kalır. Bu da dövmenin kalıcı olmasina sebep olur (3).

Dövmeler son yıllarda gençler arasında oldukça yaygınlaşmıştır. Buna bağlı olarak dövmeyi sildirme oranı da artmaktadır. Bu da bilim adamlarını daha güvenilir, yan etkisi ve maliyeti az, daha kısa sürede sonuç veren tedavi yöntemleri araştırmak için motive etmiştir. Geçmişten günümüze dövme sildirme için birçok tedavi yöntemi ortaya çıkmıştır. Bunlardan bazıları; dermabrazyon, kriyocerrahi, elektro-cerrahi ve cerrahi eksizyon gibi tahrip edici tekniklerdir. Ancak bu tekniklerin yan etkisinin çok olmasından dolayı son yıllarda lazer teknolojisi gelişmiştir. Artık Q-anahtarlı lazer günümüzde dövme sildirme için altın standart haline gelmiştir. $\mathrm{Bu}$ tedavi yöntemiyle birkaç seansta farklı dalga boylarıyla farklı renklere müdahale edilerek dövme boyasının parçalanması hedeflenir (4-6).

\section{Olgu}

Anabilim Dalımıza Aralık 2017 tarihinde başvuran 29 yaşında erkek olgunun, 2015 yılında sağ omuzdan dirseğe uzanan kol dış ve iç kısmını kaplayan kırmızı, mavi, siyah, sarı renklerini içeren desenli dövme ve sol el bileğinde sadece siyah renkten oluşan dövme yaptırdığı anlaşılmıştır. Olgu, 1 yıl sonra polislik sınavlarına hazırlandığı için dövmelerini sildirmeye karar verdiğini, bu sebeple bir kliniğe başvurduğunu ifade etmiştir. İlk lazer işleminden sonra işlem bölgesinde yanıklar oluşmuştur. Yanıkların şimdi iyileştiğini, zaten hastanın kendisinin de işlem sonrası yanıkların oluşacağından haberi olduğunu belirtmiştir. İşlem başladıktan 1-2 ay sonra polislik sınavı başvurusu için ilgili makama verilmek üzere doktoru seanslar sonrasında dövmenin başarıyla silineceğine dair imzalı yazı vermiştir. İlk 3 seansta gözle görülür değişiklik olacağını söylediklerini ancak hastanın dövmesinin hala silinmemesi üzerine son seansına gitmediğini, diğer 5 seansına gittiğini, gittiği seans başına 1300 TL ödediğini, ilk 4 seansı peşin ödeyince son 2 seansın hediye olduğunu, dava ile ödediği parasının kendisine iade edilmesini istediğini belirtmiştir.

Ekte gönderilen şahsın ve doktorun imzaladığı 2016 tarihli lazer uygulamaları ve bilgilendirme formunda; lazer epilasyon işlemiyle tüylerin tekrar çıkmayacağı garantisinin verilmediği, lazerin dövme sildirmede kullanım amacının boyanın cilt altında lazer ışınıyla parçalanması olduğunu (onam formunda lazerle dövme sildirme işleminde sonuç garantisiyle ilgili olumlu ya da olumsuz herhangi bir bilgi yer almamaktadır), yan etki olarak uygulama kısmında kızarma, kaşıntı, yanma hissi, kısa süreli ağrı, ödem, su toplaması, kabuklanma, soyulma, deride açık ve koyu lekelenme (3-12 ay arasında sürebildiği), yüzeysel yanık, çok nadir olarak iz ve morarma görülebildiği belirtilmiştir.

Hastanın Anabilim dalımızda yapılan muayenesinde sağ omuzdan dirseğe uzanan kol dış ve içini kaplayan dövmenin işlem öncesi 2016 tarihli fotoğrafla karş1laştırıldığında silinmediği, renginin solmakla birlikte halen dövme deseninin ve kırmızı, mavi, siyah, sarı renklerinin belirgin olduğu, dövmenin renginden dolay1 gözükmeyen ama dokunmakla hissedilen yer yer 0,5 cm'lik çizgi şeklinde skar izleri olduğu, sol el bileğinde ise sadece siyah renkten oluşan dövmenin 2016 tarihli fotoğrafla karşılaştırıldığında siyah rengin solduğu ama halen desenin ve rengin belirgin olduğu tespit edildi (Şekil 1 ve Şekil 2).
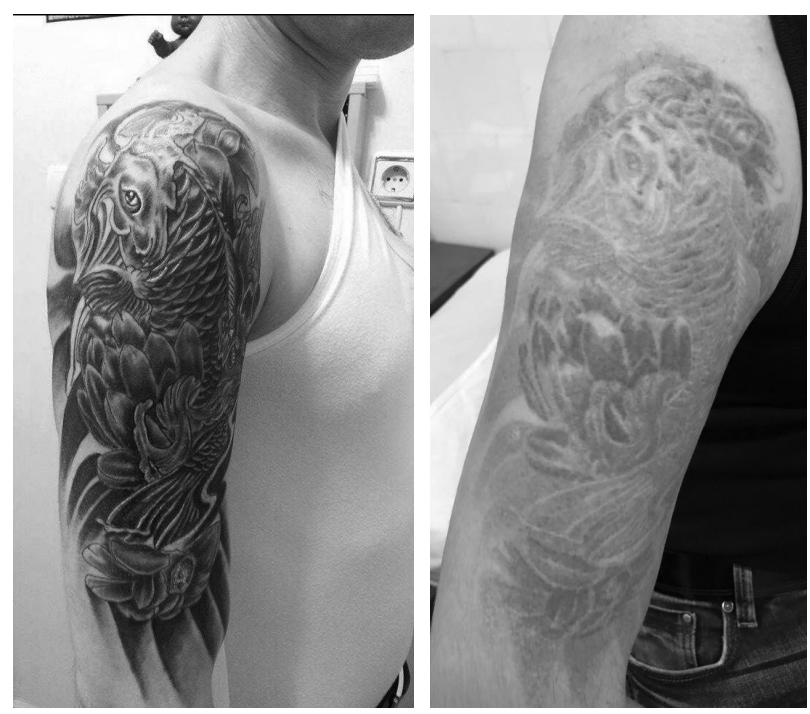

Şekil 1. Hastanın lazer uygulama öncesi ve sonrası kol fotoğrafları. 


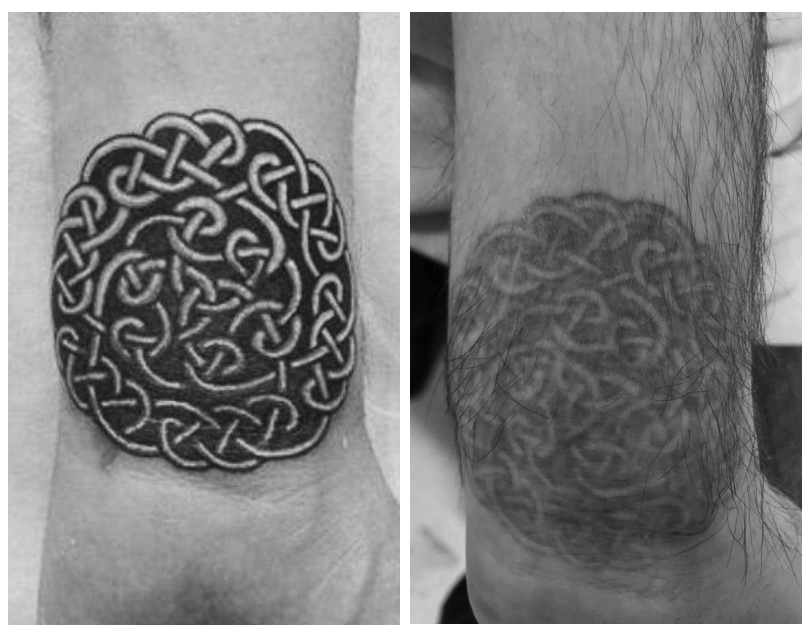

Şekil 2. Hastanın lazer uygulama öncesi ve sonrası el bileği fotoğrafları.

Mahkemede görülmekte olan Tüketici Koruma Kanunundan Kaynaklanan (hizmetin ayılı olmasından kaynaklanan) dava nedeniyle; hastanın tüm tedavi evrakları yazı ekinde gönderilmiş olmakla, davacının dosyaya sunulan işlem öncesi dövme fotoğrafları incelenerek yapılan işlemin bu tip işlerde olması gereken, çağdaş tıp gereklerine uygun kabul edilebilecek şekilde yapılıp yapılmadığının, mevcut işlem sonrası durumun önceki duruma nazaran kötüleşme olarak kabul edilip edilemeyeceği bu kapsamda varılan sonuçtan ziyade izlenen yöntemin doğru olup olmadığının tespiti hususunda raporunun düzenlenerek mahkemeye gönderilmesinin istenilmesi üzerine şahsın muayenesi yapılarak dosyası tetkik edildi. Olgu, Plastik, Rekonstrüktif ve Estetik Cerrahi Anabilim Dalı öğretim üyesine danışıldı.

Kişinin yapılan muayenesinde; sağ omuzdan dirseğe uzanan kol dış ve içini kaplayan kalıcı dövmenin, renginin solduğunun görüldüğ̈̈, bu tür işlemlerde lazer uygulamasının tıbbi bilgi ve standartlara uygun işlem olarak kabul edilmekle birlikte, 2017 tarihli ilgili makama hitaben yazılan yazıda belirtilen dövmelerin tamamen kaybolacağı şeklindeki ifadenin gerçekleşmemiş olduğunun, sonucun garanti edilmesine rağmen edimin yerine getirilmediğinin anlaşıldığı, işlem öncesi 2016 tarihli fotoğrafla karşılaştırıldığında dövmenin silinmediği kanaatinde olduğumuz raporlanmıştır.

\section{Tartışma ve Sonuç}

Dövme yaptırma oranı arttıkça buna bağlı dövme sildirme oranları da artmaktadır. Dövme sildirme oranları arttıkça komplikasyon oranı az, ağrısız, oldukça çabuk sonuç verebilen güvenilir tedavi yöntemleri de gelişmeye başlamıştır. Günümüzde de yaygın olarak kullanılan lazerle sildirme yöntemi de bu yöntemlerden biridir. Kalıcı dövmeler Q-anahtarlı lazerle silinir (7). Dövme çıkarma işleminde kullanılan farklı dalga boylarıyla farklı renklere etki eden Q-anahtarlı lazerler Tablo 1'de yer almaktadır $(8,9)$.

Lazerle farklı dalga boyları ve frekanslariyla fark11 renklere müdahale edilir. Dövmeyi silmek için doğru lazer yöntemini seçmekle beraber dövmenin rengi, cilt tipi, hastanın yaşı, güneşe maruziyet ve retinoid tedavisi, Herpes gibi başka dermatolojik hastalıklar için tedavi alıp almadığı da önemli rol oynar $(2,10)$. Bununla birlikte dövme sildirme işlemi sonrası alerjik reaksiyonlardan pigmentlerdeki renk değişimine kadar geniş çerçevede pek çok komplikasyon gelişebilir. Ciddi komplikasyonlardan biri olan hiperpigmentasyon oluşum mekanizmasına bakacak olursak dövme mürekkebi kırmızı, kahverengi, beyaz gibi pigmentler içerdiği gibi daha sıklıkla kozmetik tatuajda kullanılan titanyum dioksit ve demir oksit içeren mürekkepler de mevcuttur ve bunların çıkarılması oldukça zordur. Lazere bağlı kısa frekanslı çok yüksek sıcaklıklarda yükseltgenme ve indirgenme reaksiyonları oluşarak demir oksit kahverengiden siyaha döner, böylece pigment koyulaşması meydana gelir $(9,11)$.

Tablo 1. Dövme çıkarma işleminde kullanılan dalga boyları ve etki ettiği renkler.

\begin{tabular}{|l|c|c|c|c|c|c|}
\hline & Siyah & Lacivert & Kırmızı & Mor & Turuncu & Yeşil \\
\hline $\begin{array}{l}\text { Q-anahtarlı } \\
\text { Nd:YAG (1064-nm) }\end{array}$ & $\checkmark$ & $\checkmark$ & & & & \\
\hline $\begin{array}{l}\text { Q-anahtarl1 } \\
\text { Nd:YAG (532-nm) }\end{array}$ & $\checkmark$ & $\checkmark$ & & $\checkmark$ & $\checkmark$ & $\checkmark$ \\
\hline $\begin{array}{l}\text { Q-anahtarl1 } \\
\text { Ruby (694-nm) }\end{array}$ & $\checkmark$ & $\checkmark$ & & & & $\checkmark$ \\
\hline $\begin{array}{l}\text { Q-anahtarl1 } \\
\text { Alexandrite (755-nm) }\end{array}$ & $\checkmark$ & & & $\checkmark$ \\
\hline $\begin{array}{l}\text { Pulsed dye pigment } \\
\text { (595-nm) }\end{array}$ & & $\checkmark$ & $\checkmark$ & & & $\checkmark$ \\
\hline
\end{tabular}




\section{$\begin{array}{ccc}\mathrm{Fe}^{+3} & 140^{\circ} \mathrm{C} & \mathrm{Fe}^{+2} \\ \text { (pas rengi) } & \underset{\cdots}{\rightarrow \cdots} & \text { (siyahrengi) }\end{array}$}

\section{$\mathrm{Ti}^{+4} \quad 140^{\circ} \mathrm{C}$ (beyaz rengi) $\underset{\cdots}{\rightarrow \ldots}$ (mavi, siyah renk)}

Şekil 1. Yazı karekterleri.

Q-anahtarlı lazerler deriye zarar vermeden dövme boyasını parçalayarak küçük parçalara ayırır. Böylece parçalanmış boyalar vücut hücrelerinin artık atabileceği boyuta gelmiştir. Pigment ne kadar yoğun ise seans sayısı orantılı olarak artar. Her dövme sildirme seansı dövme rengini ortalama \%10-20 oranında açar. Dövme sildirme işlemi 6-8 hafta aralıklarla yapılır $(8,12)$. Ancak hekimin hastadan alacağı anamneze ve hastanın yaşadığı dermatolojik problemlere de dikkat etmek gerekir. Dövmenin silinmesi için en başarılı sonuç hastanın açık tenli, güneş 1şığı almamış, en az 1 yıllık dövmeye sahip ve dövme renginin siyah, mavi olduğu hastalardadır. Sarı renkli dövmelerde ise gerekli lazer tedavisi gerçekleştikten sonra bile hala deri üst tabakasında desen ve renk kalınt1ları bulunmaktadır. Bu hususta da hastayı aydınlatılmış onamla bilgilendirmek gerekir (7).

Lazer tedavisini uygulayan hekim hastaya, ilgili makama verilmek kaydıyla işlem sonucunda dövmenin izinin kalmayacağını belirten imzalı bir belge vermiştir. Türk Borçlar Kanunu 7. Bölüm (Eser Sözleşmesi) Madde 470 ve Yargitay'ın 15. HD. 3.11.1999, 4007 E./3868 karar metninde yer alan (13), hekim hastanın istediği sonucu elde edebileceği ve tedavinin sonucunun hekimin faaliyetlerinin dışında etkenlere bağlı olmadığı bir durumda, hekimin sözleşmeyle tedavinin sonucunu garanti etmiş olduğu duraksamaya yer olmayacak şekilde anlaşılabiliyorsa, istenilen sonuca ulaşamamış olması, hekimin borcun ifasını gereği gibi yapmamış sayılmasına neden olur ve hekimin borcu sözleşmeden doğan bir tazminat borcuna dönüşür. Hekimlik mesleği sonucu garanti eden bir meslek olmamakla beraber estetik operasyonlar, protez, ortodonti gibi diş tedavileri eser sözleşmesi kapsamında değerlendirilir. Hastanın başvuru nedeni ve isteği de göz önüne alındığında garanti edilen sonuca ulaşamaması özen borcunun ihlal edildiği anlamına gelir (14). Bu olgularda aydınlatılmış onam özellikle büyük önem arz etmektedir. Bu nedenle hekimler olgu özelinde yapılabileceklerin sınırlarını iyi çizmeli, bunu da aydınlatılmış onamında belirtmelidir. Vakamızda hasta ve hekim tarafindan imzalanan onam formunda, lazerle dövme sildirme işlemi sonucuyla ilgili olumlu veya olumsuz bir bilgi yer almamaktadır. Yargıtay kararlarında istenen sonuçla ilgili (sağlanıp sağlanamayacağı) ifadenin net olarak onam formunda yer alması gerektiği belirtilmiştir. Ayrıca hazır onam formları tek başına yeterli olmamakta, bu formların her hasta için özel hale getirilmesi gerekmektedir. Sözel verilen garantilerden ziyade net sınırları olan aydınlatılmış onamla hastaların bilgilendirilmesi gerekmektedir.

\section{Kaynaklar}

1. Dorfer L, Moser M, Bahr F, et al. A medical report from the stone age?. Lancet. 1999;354(9183):1023-1025. DOI: https://doi.org/10.1016/S0140-6736(98)12242-0

2. Ho SG, Goh CL. Laser tattoo removal: A clinical update. J Cutan Aesthet Surg. 2015;8:9-15.

3. Zelickson BD, Mehregan DA, Zarrin AA, et al. Clinical, histologic, and ultrastructural evaluation of tattoos treated with three laser systems. Lasers Surg Med 1994;15:364-72.

4. McDowell F. Plastic surgery: Removal of commercial tattoos of the skin. West J Med 1976;125:143.

5. Dvir E, Hirshowitz B. Tattoo removal by cryosurgery. Plast Reconstr Surg 1980;66:373-9.

6. Groot DW, Arlette JP, Johnston PA. Comparison of the infrared coagulator and the carbon dioxide laser in the removal of decorative tattoos. J Am Acad Dermatol 1986;15:518-22.

7. Özmen İ, Arca E. Lazer uygulamaları öncesinde ve sonrasında dikkat edilmesi gereken hususlar. Sürekli EğitimContinuing Medical Education. 2012; 46 Özel say1 1:7-9. DOI: https://doi.org/10.4274/turkderm.46.s1.02

8. Serup J, Bäumler W. Diagnosis and Therapy of Tattoo Complications With Atlas of Illustrative Cases. Karger. 2017.p.106. ISBN: 978-3-318-05977-9. e-ISBN: 978-3-318-05978-6. DOI: https://doi.org/10.1159/isbn.978-3-318-05978-6

9. Choudhary S, Elsaie ML, Leiva A, Nouri K. Lasers for tattoo removal: a review. Lasers Med. Sci. 2010;25(5): 61927. DOI: https://doi.org/10.1007/s10103-010-0800-2

10. Kuperman BM, Levine VJ, Ashinoff R. Laser removal of tattoos. Am J Clin Dermatol. 2001;2(1):21-5.

11. Çalışkan E. Tatuajda Lazer. Sürekli Eğitim- Continuing Medical Education. 2012; 46 Özel say1 1:30-5. DOI: https:// doi.org/10.4274/turkderm.46.s1.06

12. Lee CN, Bae EY, Park JG, Lim SH. Permanent make up removalusing Q-switched Nd: YAG laser. Clin. Exp. Dermatol. 2009; 34 (8): e594-6. DOI: https://doi.org/10.1111/ j.1365-2230.2009.03268.x Epub 2009Jul 2.

13. Arınc1 A, Usta S. The Legal Responsibility of the Doctor of Medicine in the Aesthetic- Purpose Medical Interventions and The Contract for Work and Services. Turk J Plast Surg 2017; 25(2): 84-93. DOI: https://doi.org/10.5152/TurkJPlastSurg.2017.2152

14. Gökcan HT. Tıbbi Müdahaleden Doğan Hukuki ve Cezai Sorumluluk. Güncellenmiş 2. Baskı. Seçkin Yayıncılık San. ve Tic. A. Ş. Ankara, Ekim 2014:131-132. 